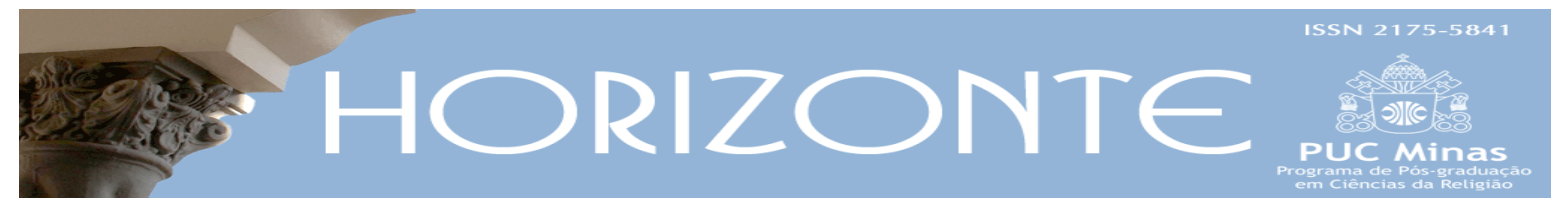

Dossiê: Política, Mídia e Religião - Comunicação (c) (i)

\title{
Viver a esperança: \\ uma reflexão sobre espiritualidade e mística em vista da manutenção da esperança a partir da Fratelli tutti
}

\author{
Living the hope: \\ a reflection on spirituality and mystics in view of the management of hope \\ from the Fratelli tutti
}

Ceci Maria Costa Baptista Mariani ${ }^{1}$

\begin{abstract}
Resumo
A Encíclica Fratelli tutti, do Papa Francisco, publicada em 3 de outubro de 2020, é, como se tem veiculado, um documento que faz parte da Doutrina Social da Igreja. Escrita sob a inspiração do diálogo com o líder islâmico Grande Imã Ahmad AlTayyeb, pretende falar sobre o amor fraterno em sua dimensão universal. Este comentário, unindo-se a outros que se tem feito sobre esse texto, tem como objetivo contribuir na recepção da encíclica, sendo uma abordagem na perspectiva da espiritualidade.
\end{abstract}

Palavras-chave: Fratelli tutti. Papa Francisco. Esperança. Espiritualidade. Diálogo.

\begin{abstract}
The Encyclical Fratelli tutti by Pope Francis, published on October 3rd of 2020, is, as has been reported, a document that belongs to the Church's Social Doctrine agenda. Written over the inspirational dialogue with the islamic leader Great Imã Ahmad AlTayyeb, it intends to discuss fraternal love in its universal extent. This commentary, in conjunction with others that have been made about the text in question, seeks to contribute to the encyclical reception, as an approach from the perspective of spirituality.
\end{abstract}

Keywords: Fratelli tutti. Pope Francis. Hope. Spirituality. Dialogue.

Comunicação submetida em 3 de março de 2020 e aprovada em 24 de agosto de 2020.

${ }^{1}$ Doutora em Ciências da Religião pela PUC-SP. Professora da PUC-Campinas. País de origem: Brasil. E-mail: cecibmariani@gmail.com 


\section{Introdução}

No evangelho, encontra-se uma parábola muito conhecida por todos, mas, talvez, melhor compreendida pelos pobres, aqueles que são acostumados a lidar com a terra ruim: é a parábola do semeador (Mt 13, 3b-9; Lc 8, 4-8).

Um semeador saiu a semear, diz a parábola, e semeia em todo tipo de solo. $\mathrm{Na}$ terra boa, mas também na que está à beira do caminho, nas pedregosas e com espinhos. Terras em que as sementes estavam sujeitas a ser roubadas por pássaros, sufocadas pelos espinhos ou ter seus brotos queimados pelo sol. É uma parábola que fala da confiança na bondade do mundo e também de esperança, apesar dos percalços da vida.

Ouvindo a parábola, podemos pensar que Jesus falava de si mesmo e da maneira como exercia sua missão de semear a boa palavra a todos, sabendo das tantas dificuldades para sua frutificação. Jesus, comenta Pagola (2013, p. 152), partilha do realismo e da confiança de lavradores da Galileia, que sabiam que "a semeadura se perderia em mais de um lugar naquelas terras desiguais”, e não desanimavam, pois, o importante era a colheita final. Tinham confiança em que, apesar dos obstáculos ou das resistências, a semente que encontrasse terra boa frutificaria.

Não obstante as densas sombras que cobrem nosso mundo atual, Francisco, em sua encíclica Fratelli tutti, deseja "dar voz a tantos percursos de esperança”, pois crê, como o semeador que saiu a semear, que "Deus continua a espalhar sementes de bem na humanidade" e que a pandemia "permitiu-nos recuperar tantos companheiros e companheiras de viagem que, no medo, reagiram dando a própria vida.” (FT, 54)². Entre eles, podemos lembrar um médico brasileiro, de quem conhecemos rosto e voz: Lucas Augusto Pires, que atuava na linha de frente

\footnotetext{
${ }^{2}$ As chamadas indicam a sigla da encíclica (Fratelli tutti) e o parágrafo correspondente (FRANCISCO, 2020).
} 
do combate à Covid-19 no Instituto de Saúde Bom Jesus, em Ivaiporã (PR). Antes de ir para a UTI, devido ao agravamento do quadro de Covid-19, escreveu em uma rede social: "Peguei essa doença fazendo o que amo, cuidando dos meus pacientes com amor e dedicação. Faria tudo outra vez” (EPTV1, 2020). Na encíclica, escrita com base na conversa com o líder islâmico Grande Imã Ahmad Al-Tayyeb, Francisco pretende falar sobre o amor fraterno em sua dimensão universal e, como fez na Laudato’si, abrir diálogo com todas as pessoas de boa vontade.

Entre as muitas sombras, denunciadas na encíclica, podemos ressaltar a excelente avaliação sobre a paradoxal experiência de comunicação possibilitada pelo advento da internet e a invenção das redes sociais (FT, 42-50). No contexto da tragédia global provocada pela pandemia da Covid-19, que obrigou as pessoas ao distanciamento social, acirraram-se, nesse âmbito, as contradições. No espaço cibernético das trocas comunicacionais, crescem as atitudes fechadas e intolerantes, reduz-se a distância a ponto de deixar de existir o direito à intimidade, e tudo é exposto de forma espetacular para ser observado e controlado. Proliferamse, assim, movimentos digitais de ódio.

A encíclica ainda alerta para o risco da dependência, do isolamento e da perda de contato com a realidade concreta. Perde-se aquilo que é contribuição do corpo para a comunicação: "gestos físicos, expressões do rosto, silêncios" e também “o perfume, o tremor das mãos, o rubor, a transpiração” (FT, 43). O mundo, com tantos recursos comunicacionais, é um mundo surdo, afirma Francisco. Em meio ao frenesi da comunicação cada vez mais veloz, perderam-se o silêncio e a escuta, "não se presta mais uma atenção penetrante e prolongada ao coração da vida, nem se reconhece o que é essencial para dar um sentido à existência.” (FT, 50).

Contudo, mesmo diante dessas e de outras tantas sombras que cobrem a civilização global, é importante ter atenção ao perigo do pessimismo: “Ao engano de que 'tudo vai mal' corresponde o dito 'ninguém o pode consertar. Sendo assim, que posso fazer eu?’ Desse modo, alimenta-se o desencanto e a falta de esperança.” (FT, 76). 


\section{Olhar para si mesmo}

Para retomar a esperança de um mundo melhor, é preciso, em primeiro lugar, olhar para si mesmo. Esse é um conselho que se encontra no ensinamento dos vários mestres espirituais. A esperança fundada numa atitude alienada diante da realidade é uma falsa esperança. Como seres de relação, cientes de que tudo está interligado e que a identidade de cada um se constitui na relação com o outro, fazse necessário examinar as próprias atitudes diante dos outros, especialmente dos que estão “caídos à margem da estrada”. É preciso vencer a tentação da indiferença, aconselha Francisco. A esperança requer o cultivo de uma forma de amar que ultrapasse o amor aos que já nos são próximos porque pertencem a nosso círculo familiar ou de amizade. A verdadeira transformação desse mundo supõe uma abertura mais ampla à alteridade, um “amor universal”.

Sendo seres sociais, estamos sempre expostos a encontros desafiadores. Num mundo como este em que estamos vivendo, estruturado sobre a exploração do trabalho, vivenciamos constantemente a luta interior provocada pelo encontro com o outro necessitado de cuidado (FT, 69). Na crise sanitária que estamos enfrentando, o desafio é ainda maior.

A parábola do bom samaritano, lembra o Papa Francisco, é uma narrativa que nos inspira a cultivar o amor universal. Ela ensina que não importa indagar quem é o próximo, mas, sim, estar perto daquele que necessita de cuidado, ultrapassando os preconceitos (FT, 80). É um texto que nos convida a fazer ressurgir nossa vocação de cidadãos do próprio país e do mundo inteiro, enquanto construtores de um vínculo social (FT, 66). "A narração não desenvolve uma doutrina feita de ideais abstratos, nem se limita à funcionalidade de uma moral ético-social” (FT, 68), mas revela o humano como ser criado para o amor, isto é, para o cuidado do outro. O cuidado, podemos lembrar, é uma categoria que, desde os anos 1980, tem ganhado destaque no mundo da filosofia, das ciências da vida e da teologia. A categoria do cuidado introduz na história, pela primeira vez, a 
consideração da responsabilidade ontológica intrínseca dos humanos para consigo, para com os outros e para com tudo. 3

A verdade de si se revela no encontro com o outro. Apoiada numa antropologia teológica em diálogo com a filosofia existencialista, a encíclica afirma que o ser humano só reconhece a própria verdade no encontro com o outro: "ninguém pode experimentar o valor de viver, sem rostos concretos a quem amar" (FT, 87). $\mathrm{O}$ amadurecimento da personalidade se faz num processo de abertura que começa no encontro com aqueles que fazem parte do círculo mais próximo e se estende, ganhando uma amplitude social.

\section{No encontro com o outro se encontra o mistério de Deus}

O exercício da hospitalidade, virtude reconhecida como fundamental para a construção de um outro mundo possível (BOFF, 2005b), é a maneira concreta de vivenciar o encontro com a humanidade para além do próprio grupo (FT, 90): “o amor coloca-nos em tensão para a comunhão universal. Ninguém amadurece nem alcança a sua plenitude, isolando-se" (FT, 95), afirma Francisco. A "amizade social" e a "fraternidade universal" supõem ir além do individualismo e encontrar-se com o outro reconhecendo sua dignidade de forma incondicional.

A "amizade social" com abertura universal, não deve ser, entretanto, "universalismo autoritário e abstrato, ditado ou planificado por alguns e apresentado como um presumível ideal para homogeneizar, dominar e saquear" (FT, 100). O Papa Francisco denuncia um modelo de globalização que, em nome da uniformidade, destrói a riqueza e singularidade de cada pessoa e de cada povo. A amizade social e a fraternidade universal devem significar abertura ao outro em sua existência concreta, especialmente aos que estão em situação de maior fragilidade.

\footnotetext{
${ }^{3}$ O teólogo Leonardo Boff, lançando um olhar para essa compreensão de cuidado a partir da realidade latino-americana, e contrapondo o modo de ser "cuidado" ao modo de ser "trabalho", explicita suas consequências sociais, políticas e ecológicas: à diferença do modo de ser "trabalho", que é o modo de ser humano do mundo ordenado pela racionalidade, o modo de ser "cuidado" privilegia a corporeidade, leva a uma concepção da realidade como um todo orgânico, diverso e sempre includente, em que tudo se encontra interligado. Não vê a natureza como objeto, não estabelece com ela uma relação de dominação, mas uma relação de parceria. Ao contrário do modo de ser "trabalho", fundado no distanciamento objetivo, o "cuidado" supõe proximidade, sintonia, acolhimento. Para Leonardo Boff (2005a), o modo de ser "cuidado", associado simbolicamente ao feminino, foi sufocado pela "ditadura do trabalho" imposta pela revolução industrial.
} 
Do ponto de vista da espiritualidade, podemos dizer que os desafios atuais pedem uma "mística de olhos abertos" às vítimas de um estilo de vida regido pelos critérios da liberdade de mercado e da eficiência que se impôs na sociedade em nível global (FT, 110). É preciso deixar-se interromper, propõe Metz (2013), pelo sofrimento dos outros.

Ao nos permitirmos a isso, temos nossos desejos e preferências relativizados. Para Metz (2013), uma revolução antropológica se opera por essa interrupção; uma força de oposição que capacita para a interrupção dos contextos terrenos da violência é o que define o espírito pentecostal: graça de Deus que ensina "aos corações a arte de parar e dar meia volta, quando o 'Adão' natural tenta sempre prosseguir." (p. 139). Espírito e graça expressam-se como força de oposição quando a opressão geral das reproduções sociais exige que tudo continue da maneira como está.

A mística que se faz "de olhos abertos" para os sofredores desse mundo, obedecendo a autoridade deles, é uma mística que não se restringe a uma tradição religiosa, mas tem um sentido universal, uma vez que a autoridade das vítimas é a que deve valer para todos (METZ, 2013, p. 71). A mística de olhos abertos é, portanto, uma mística inspirada na justiça de Deus, que desce e se coloca ao lado do sofredor para salvar o mundo pelo poder da compaixão, solidariedade e comunhão.

Na América Latina, a mística de olhos abertos se fez notar de maneira admirável. A irrupção dos pobres que tomam consciência de que sua situação é fruto de injustiça estrutural ganha, aqui, um sentido profético - capta-se nessa luta uma força divina de libertação. Neste sentido, pode-se dizer que, na relação com o outro, descobre-se o mistério de Deus, e não se pode deixar de ver, em Francisco, as marcas da experiência latino-americana. 
Neste mundo de grande mobilidade humana, grande desafio para a vivência da hospitalidade, surge o complexo desafio das migrações a partir do problema da tensão entre o local e o global. Sobre isso, vale citar as palavras contundentes de Francisco:

É preciso olhar para o global, que nos resgata da mesquinhez caseira. Quando a casa deixa de ser lar para se tornar confinamento, calabouço, resgata-nos o global, porque é como a causa final que nos atrai para a plenitude. Ao mesmo tempo temos de assumir intimamente o local, pois tem algo que o global não possui: ser fermento, enriquecer, colocar em marcha mecanismos de subsidiariedade. Portanto, a fraternidade universal e a amizade social dentro de cada sociedade são dois polos inseparáveis e ambos essenciais. Separá-los leva a uma deformação e a uma polarização nociva. (FT, 142).

A riqueza do local não deve perder o horizonte universal. Se o encontro for regido pela gratuidade, o ganho será uma nova síntese que beneficiará todas as partes. A diversidade deve, pois, ser acolhida como dom, não como problema.

\section{A dimensão social e política da esperança}

A esperança não é uma experiência individual. Não se pode deixar de reconhecer que a fraternidade universal e a amizade social requerem uma política melhor. Fé e política não são alternativas que se excluem, é preciso revalorizar a política como vocação humana, afirma Francisco (FT, 180). A "mística de olhos abertos", que, para Metz, é o rosto atual da mística cristã, tem um viés declaradamente político. Francisco denuncia o desprezo pelos vulneráveis operado por formas populistas de fazer política e também por formas liberais que se colocam a serviço dos interesses econômicos dos poderosos (FT, 155), ressaltando que a política não deve se submeter à economia nem ceder ao paradigma eficientista da tecnocracia.

Para um mundo melhor, é necessário que haja uma política com visão ampla e disposição para uma reformulação integral iluminada pelo diálogo interdisciplinar, que pode esclarecer os vários aspectos da crise (FT, 177). Uma 
política que seja conduzida por uma "caridade social”, recomenda o Papa, que é o amor expresso nas macrorrelações, como relacionamentos sociais, econômicos e políticos (FT, 170). Uma "caridade social”, ele esclarece, que não deve ser prisioneira de sentimentalismo subjetivo, mas prezar pela objetividade e empenhar-se na busca da verdade para além de relativismos, contando "também com o desenvolvimento das ciências e a sua contribuição insubstituível para encontrar os percursos concretos e mais seguros para alcançar os resultados esperados.” (FT, 185).

Além disso, no mundo globalizado, a política também deve ser considerada em sua amplitude internacional. Francisco, retomando o encontro com o Grande Imã Ahmad Al-Tayyeb, pede aos artíficies da política e da economia mundiais que se comprometam com a difusão da tolerância, da convivência e da paz (FT, 192).

A abertura ao diálogo é, hoje, uma atitude fundamental. No contexto de diversidade em que vivemos, o fechamento ao outro é uma recusa ao crescimento. Para o diálogo, observa o Papa Francisco, não basta ter espaço para falar, como acontece nas redes sociais, lugar em que pessoas reagem emitindo opiniões, muitas vezes em tom alto e agressivo; para que o diálogo de fato aconteça, é preciso que se cultive a disposição para escutar.

Rubem Alves (1967) escreve, na crônica intitulada "Escutatória”, sobre a dificuldade que as pessoas têm de ouvir. Todo mundo quer aprender a falar, e falar bem, por isso a existência dos cursos de oratória. Mas ninguém quer aprender a ouvir, ele afirma, pois escutar é complicado e sutil, e para escutar é preciso esvaziar a cabeça. Ademais, ele acrescenta, "a nossa incapacidade de ouvir é a manifestação mais constante e sutil da nossa arrogância” (p. 67). Para ouvir, é preciso fazer silêncio. "Para mim”, ele diz, "Deus é isto: a beleza que se ouve no silêncio. Daí a importância de se ouvir os outros: a beleza mora lá também. Comunhão é quando a beleza do outro e a beleza da gente se juntam num contraponto." (p. 71). 
O diálogo social necessário à constituição de uma nova cultura global inclusiva pressupõe o respeito ao ponto de vista do outro, suas convicções e seus interesses, acreditando que é na resolução das tensões que se encontra o progresso (FT, 203). A base do consenso, reflete Francisco, não é a aceitação do relativismo, mas a busca da verdade, que deve estar na base de nossas opções e leis. Uma verdade que pode ser conhecida pela razão que indaga sobre a natureza humana (FT, 208).

É importante ressaltar, entretanto, que, para Francisco, o reconhecimento do que deve ser afirmado e respeitado para além do consenso ocasional se dá por meio do diálogo (FT, 211): “a inteligência pode perscrutar a realidade das coisas, através da reflexão, da experiência e do diálogo, para reconhecer nessa realidade que a transcende a base de certas exigências morais universais.” (FT, 213).

No horizonte de nossa esperança, deve estar "uma cultura do encontro" em que todos devem ser incluídos: "falar 'cultura do encontro' significa que nos apaixona, como povo, querer encontrar-nos, procurar pontos de contato, lançar pontes, projetar algo que envolva todos. Isto tornou-se uma aspiração e um estilo de vida" (FT, 216). Para falar dela, Francisco cita um verso do poema "Samba da benção”, de Vinícius de Moraes: “A vida é a arte do encontro, embora haja tanto desencontro na vida” (FT, 215). Essa arte supõe, é fato, grande dedicação. A paz social pede esforços em "gerar processos que possam construir um povo capaz de recolher as diferenças" (FT, 217) - é preciso recuperar a amabilidade.

Isso faz lembrar outro poeta brasileiro, não tão reconhecido como o primeiro. Um poeta popular que, enlouquecido por ter presenciado um grande incêndio que vitimou cerca de 400 pessoas, deixou tudo para consolar as pessoas enlutadas, atingidas pela tragédia. No local do incêndio, fez um poço artesiano, plantou flores e começou a escrever mensagens na carroceria de seu caminhão. 
José Datrino, que até aquele momento era caminhoneiro e dono de uma pequena transportadora, transforma-se no Profeta Gentileza. Com o passar do tempo, sai do local do circo, começa a percorrer as ruas do Rio de Janeiro e passa a pregar na barca que faz a trajetória entre o Rio e Niterói. Na bata que vestia, vinha escrito: "Gentileza é o remédio de todos os males, amorrr [sic] e liberdade" e "Não usem problemas, não usem pobreza, usem amorrr [sic] Gentileza” (GUELMAN, 2000 apud ROCHA, 2018, p. 261). Na década de 1980, ele decide transformar as 56 pilastras do viaduto do Gasômetro em tábuas de seus ensinamentos. Com letras garrafais e grafia própria, escreve mensagens que pedem amor e paz. Em uma delas, podemos ler: "Este é o profeta gentileza que gera gentileza com amorrr [sic] e paz para um Brasil e um mundo melhor meus filhos não usem problemas usamos a natureza”.

“A amabilidade é libertação da crueldade que às vezes penetra nas relações humanas”, escreve Francisco (FT, 224). O exercício da amabilidade, quando esta se torna cultura, "transforma o estilo de vida, as relações sociais, o modo de debater e confrontar as ideias. Facilita a busca de consensos e abre caminhos onde a exasperação destrói todas as pontes.” (FT, 224).

\section{Considerações finais}

Enfim, não podemos deixar que nos roubem a esperança! (EG, 86) O desafio é romper com a cultura do individualismo. Um novo encontro, propõe Francisco, deve ser uma construção artesanal que conte com o envolvimento de cada um com o bem comum. A paz, nesse contexto de grande diversidade, coloca para cada um a exigência de assumir o compromisso com o todo, sem deixar o próprio lugar de pertença, mas ultrapassando seus interesses particulares.

Esse novo encontro, para ser duradouro, pede, entretanto, uma revisão cuidadosa dos desencontros, de seus motivos e causas. Pede que se encare a verdade sem dissimulação: 
a verdade não deve levar à vingança, mas antes à reconciliação e ao perdão. A verdade é contar às famílias dilaceradas pela dor do que aconteceu com os seus parentes desaparecidos. A verdade é confessar o que aconteceu aos menores recrutados pelos agentes de violência. A verdade é reconhecer o sofrimento das mulheres vítimas de violência e de abuso. (FT, 221).

A cultura do encontro e a construção artesanal da paz devem ser apoiadas no perdão: “A verdadeira reconciliação não escapa do conflito, mas alcança-se dentro do conflito, superando-o através do diálogo e de negociações transparentes, sinceras e pacientes" (FT, 228). Nada deve ser esquecido - a Shoah, os bombardeios atômicos de Hiroxima e Nagasáqui, as perseguições, o comércio de escravos, os massacres étnicos, e tantos outros fatos. Os que perdoam, afirma Francisco, não esquecem, "mas renunciam a deixar-se dominar pela mesma força que os lesou" (FT, 251). O perdão, ele acrescenta, "é precisamente o que permite buscar a justiça sem cair no círculo vicioso da vingança nem na injustiça do esquecimento" (FT, 252). Duas situações extremas, vistas como solução em circunstâncias dramáticas, devem ser rejeitadas: a guerra e a pena de morte.

Falando como líder religioso num mundo de grande pluralidade religiosa, Francisco assume que as religiões têm a missão comum de atuar pela construção da fraternidade e a defesa da justiça, estabelecendo entre si um diálogo que vá além da diplomacia, da amabilidade ou da tolerância (FT, 271). Sem se colocar como portavoz de uma tradição detentora da verdade, afirma, ainda, que as religiões, a partir da experiência de fé e da sabedoria acumuladas por séculos, mas contando também com o que aprenderam de suas fraquezas e quedas (FT, 274), têm muito a contribuir nessa empreitada. Convoca os líderes religiosos para que atuem como verdadeiros mediadores (e não apenas intermediários) nos conflitos desencadeados pela violência fundamentalista, tão presente na atualidade. Os intermediários, ele afirma, procuram contentar todas as partes e tirar vantagens em benefício próprio. $\mathrm{O}$ mediador atua com gratuidade: não reserva nada para si, mas dedica-se generosamente "até se consumir, consciente de que o único lucro é a paz" (FT, 284). 
A encíclica termina, enfim, com duas orações. A primeira, numa perspectiva inter-religiosa, dirigida ao "Senhor e Pai da humanidade" (FT, 287), pedindo que o criador inspire em suas criaturas o sonho de um novo encontro, de diálogo, de justiça e de paz, e que nos dê um coração aberto para que se possa estabelecer entre os povos e nações da terra "laços de amizade, de projetos comuns, de esperanças compartilhadas” (FT, 287). A segunda, numa perspectiva ecumênica, é dirigida à Trindade de amor. Ao Pai, que infunda em nós amor fraterno; ao Filho, que nos ajude a vê-lo "crucificado nas angústias dos abandonados e dos esquecidos desse mundo" (FT, 287); e ao Espírito Santo, que nos mostre "a sua beleza refletida em todos os povos da terra, para descobrirmos que todos são importantes, que todos são necessários, que são rostos diferentes da mesma humanidade amada por Deus” (FT, 287).

\section{REFERÊNCIAS}

ALVES, R. O amor que acende a lua. Campinas: Papirus, 1999.

BÍBLIA DE JERUSALÉM. São Paulo: Paulinas, 1981.

BOFF, L. O cuidado essencial: princípio de um novo ethos. Inclusão Social, Brasília, v. 1, n. 1, p. 28-35, out./mar. 2005a.

BOFF, L. Virtudes para um outro mundo possível: hospitalidade: direito e dever de todos. Petrópolis: Vozes, 2005b. Volume 1.

EPTV1. Médicos do HC lamentam morte de neurocirurgião que atuou em separação de siamesas: 'mundo perdeu uma alma do bem'. G1, Rio de Janeiro, 10 ago. 2020. Disponível em: <https://g1.globo.com/sp/ribeirao-pretofranca/noticia/2020/o8/10/medicos-do-hc-lamentam-morte-de-neurocirurgiaoque-atuou-em-separacao-de-siamesas-mundo-perdeu-uma-alma-do-bem.ghtml >. Acesso em: 2 nov. 2020.

FRANCISCO. Fratelli tutti: sobre a fraternidade e a amizade social. 2020. Disponível em:

<http://www.vatican.va/content/francesco/pt/events/event.dir.html/content/vati canevents/pt/2020/10/4/enciclica-fratellitutti.html>. Acesso em 2 nov. 2020. 
FRANCISCO. Evangelii gaudium: a alegria do evangelho. Disponível em: file://C:/Users/infra/Documents/1-CECIBM/PapaFrancisco/papafrancesco_esortazione-ap_20131124_evangelii-gaudium.pdf. Acesso em: 02 nov. 2020.

METZ, J. B. Mística de olhos abertos. São Paulo: Paulus, 2013.

PAGOLA, J. A. O caminho aberto por Jesus: Mateus. Petrópolis: Vozes, 2013.

ROCHA, A. R. Ética e estética no universo Gentileza. Profecia na cena urbana do Rio de Janeiro. Teoliterária, São Paulo, v. 8, n. 15, p. 250-265, 2018. 